\title{
Effects of Processing Parameters on Mechanical Properties of Silicon Carbide Nanoparticle-Reinforced Aluminium Alloy Matrix Composite Materials
}

\author{
Hansang Kwon ${ }^{1,2}$, Mart Saarna ${ }^{3}$, and Marc Leparoux ${ }^{4, *}$ \\ ${ }^{1}$ Department of Materials System Engineering, Pukyong National University, 45, Yongso-ro, Nam-gu, Busan 48547, Korea \\ ${ }^{2}$ Next Generation Materials Co., Ltd., 365, Sinseon-ro, Nam-gu, Busan 48547, Korea \\ ${ }^{3}$ Department of Materials Engineering, Tallinn University of Technology, Ehitajate tee 5, 19086 Tallinn, Estonia \\ ${ }^{4}$ Laboratory of Advanced Materials Processing, EMPA-Swiss Federal Laboratories for Materials Science and Technology,
} Feuerwerkerstrasse 39, 3602 Thun, Switzerland

\begin{abstract}
Nano-silicon carbide (nSiC) particle-reinforced aluminium (Al) 6061 alloy matrix composites were fabricated by high-energy ball milling, hot-pressing (HP), and hot-forging (HF). The composite powders were degassed and the composites were synthesised under air and/or vacuum. Mechanical properties of the obtained composite materials were evaluated using various tests, including indentation, compression, four-point bending, and tensile tests as well as by microstructural observations. Different amounts of $\mathrm{nSiC}$ were added and the mechanical properties of the obtained composite materi-als were measured and discussed. The microstructures of the composites depended on the $\mathrm{nSiC}$ content and synthesis conditions. The Vickers hardness and tensile strength values of the $\mathrm{nSiC}$ reinforced Al 6061 composites were approximately three times higher than that of a pure $\mathrm{Al}$ 6061 alloy. The results demonstrated that the small amount of nSiC particles functioned as efficient reinforcement material in the Al 6061 alloy matrix composite material and that the strength and ductility of the composite material can be controlled by adjusting the processing parameters and nSiC content.
\end{abstract}

Keywords: Aluminium 6061, Nano-Silicon Carbide, Metal-Matrix Composite, Hot-Pressing, Mechanical Properties.

\section{INTRODUCTION}

Aluminium (Al) alloys are lightweight alloys widely used in industrial applications due to their small specific weights combined with good specific stiffnesses and strengths. These properties can be further improved by adding nanoparticles by powder metallurgy (PM) methods $[1,2]$. With the recent progress in nanoscale materials, the development of nanoreinforced composites based on metallic matrices attracts significant interest [1-3]. The main challenge in this field is to achieve a homogeneous dispersion of reinforcement particles inside the solid matrix. One approach to produce such nanoreinforced composite materials is to use high-energy milling (HEM) [4-6] of nanoscale reinforcement particles with a metallic matrix powder, followed by hot-pressing (HP).

\footnotetext{
*Author to whom correspondence should be addressed.
}

The increase in strength of a nanoparticle-reinforced structure, such as Al-alloy metal matrix composites (MMCs), is accompanied with a decrease in ductility [7, 8]. HP is a PM approach, which can be easily applied for highscale production, yielding materials with approximately full densities. Therefore, ductility improvement of hotpressed (HPed) Al-alloy MMCs is of interest. Nano-silicon carbide (nSiC) is a promising reinforcing material in the $\mathrm{Al}$ alloy matrix due to its superior chemical inertness, high strength and hardness, excellent thermal shock resistance, and relatively low density $[9,10]$. Most of the previous $\mathrm{SiC}$ reinforced $\mathrm{Al}$ matrix composites were fabricated by casting processes. Many papers reported increased hardness values of the composites; however, some of the previous papers reported reduced compressive strength, tensile strength, and hardness [11-14]. El-Daly et al. employed the $\mathrm{PM}$ method and added $\mathrm{nSiC}$ particles to pure $\mathrm{Al}$; however, no detailed experimental results on mechanical 
properties were presented $[15,16]$. PM is one of the most suitable processes to fabricate highly densified particulatereinforced Al-matrix composite materials.

In this study, nSiC particle-reinforced Al 6061 alloy matrix composite materials were fabricated by high-energy mechanical ball milling and HP methods. Al 6061 alloy was employed as the matrix material, which was demonstrated to be a suitable matrix alloy for production of MMCs with low specific weights, relatively good specific stiffnesses, and high specific strengths [17]. The obtained nSiC particle-reinforced Al 6061 alloy matrix composites underwent hot-forging (HF) under different atmospheres of air and vacuum. The effect of the $\mathrm{nSiC}$ volume fraction (1, 5, and 10 vol.\%) in the Al 6061 alloy matrix composites was investigated. The obtained composite materials were analysed in terms of mechanical properties, including hardness, flexural strength, tensile strength, and elongation.

\section{EXPERIMENTAL METHODS}

Gas-atomised Al 6061 alloy powder (TLS Technik, purity: 99.5\%, mean size: $45 \mu \mathrm{m}$ ) was used as the matrix material. The $\mathrm{nSiC}$ powder (mean size: $30 \mathrm{~nm}$ ) was produced at the EMPA Thun using the inductively coupled plasma synthesis (ICP) method; the $\mathrm{nSiC}$ fabrication is reported in detail in Ref. [18]. The Al 6061 powder and nSiC particles were mixed in a planetary ball mill (Retsch $\mathrm{GmbH}$, PM400) for $20 \mathrm{~h}$ in argon atmosphere at $360 \mathrm{rpm}$ using $\varnothing 10$-mm balls, a 10:1 ball-to-powder weight ratio, and $0.7 \mathrm{~g}$ stearic acid as a process control agent (PCA); 1-, 5-, and 10-vol.\%-nSiC Al 6061 composite powders were prepared and investigated. The powder blend was transferred into a glove-box with a controlled inert argon atmosphere where the powder was passivated for almost one week as the milled powder is in a highly activated energy state and could easily oxidise/burn in contact with air. After the passivation, the composite powder was heattreated at $450{ }^{\circ} \mathrm{C}$ for $14 \mathrm{~h}$ with different atmospheres of air and vacuum in a steel mould for removal of residual PCA and degassing.
The heat-treated mould including the composite powder was then heated up further in air atmosphere or vacuum to the desired pressing temperature of $550{ }^{\circ} \mathrm{C}$ for $1.5 \mathrm{~h}$ and pressed rapidly at a pressure of $565 \mathrm{MPa}$ for $4 \mathrm{~s}$ by a uniaxial press machine (Walter + Bai AG, Switzerland). The diameter and thickness of the obtained composites were 30 $\mathrm{mm}$ and approximately $5 \mathrm{~mm}$, respectively. The HPed composite materials were also hot-forged (HFed) at $500{ }^{\circ} \mathrm{C}$ and $280 \mathrm{MPa}$ for $30 \mathrm{~s}$ in air atmosphere or vacuum. The diameter and thickness of the HFed composite materials were $45 \mathrm{~mm}$ and $3.5 \mathrm{~mm}$, respectively. The main purpose of the heat treatment for HP and HF in different atmospheres of air and vacuum is to reveal the suitable process atmosphere for the $\mathrm{nSiC}$ particle-reinforced $\mathrm{Al}$ 6061matrix composite materials. The fabrication procedure of the $\mathrm{nSiC}-\mathrm{Al} 6061$ composites is illustrated in Figure 1. The densities of the composites were measured based on the Archimedes principle, according to the InternationalOrganisation-for-Standardisation (ISO) 3369:1975. The microstructures of the chemically etched $(30 \% \mathrm{NaOH})$ composites were observed by optical microscopy (Zeiss Axioplan light microscope) and high-resolution cold-fieldemission scanning electron microscopy (Hitachi, FE-SEM S-4800).

A Zwick ZHU 2.5 Martens hardness tester was used to obtain indentation modulus $\left(E_{\mathrm{IT}}\right)$ and Vickers hardness (HV10) values according to the standard EN-ISO 14577:2003 [19]. A loading speed of $0.2 \mathrm{~mm} / \mathrm{min}$, unloading speed of $0.1 \mathrm{~mm} / \mathrm{min}$, maximum load of $100 \mathrm{~N}$, and dwell time of $15 \mathrm{~s}$ were used. At least five results were obtained for each material. Tensile tests were performed using flat dog-bone samples with a thickness of $3.0 \mathrm{~mm}$ and $L_{o}=10 \mathrm{~mm}$ according to EN-ISO 68921:2010 [20]. The tests were performed with position control with a strain rate of $3 \times 10^{-3} \mathrm{~s}^{-1}$ using a universal testing machine (Walter + Bai AG, Switzerland); at least four specimens per sample were tested. The specimen size in the compression test was chosen according to Ref. [21]; a 150-kN Walter and Bai servo-hydraulic test machine was used to measure the deformations of the specimens. The test was performed with position control

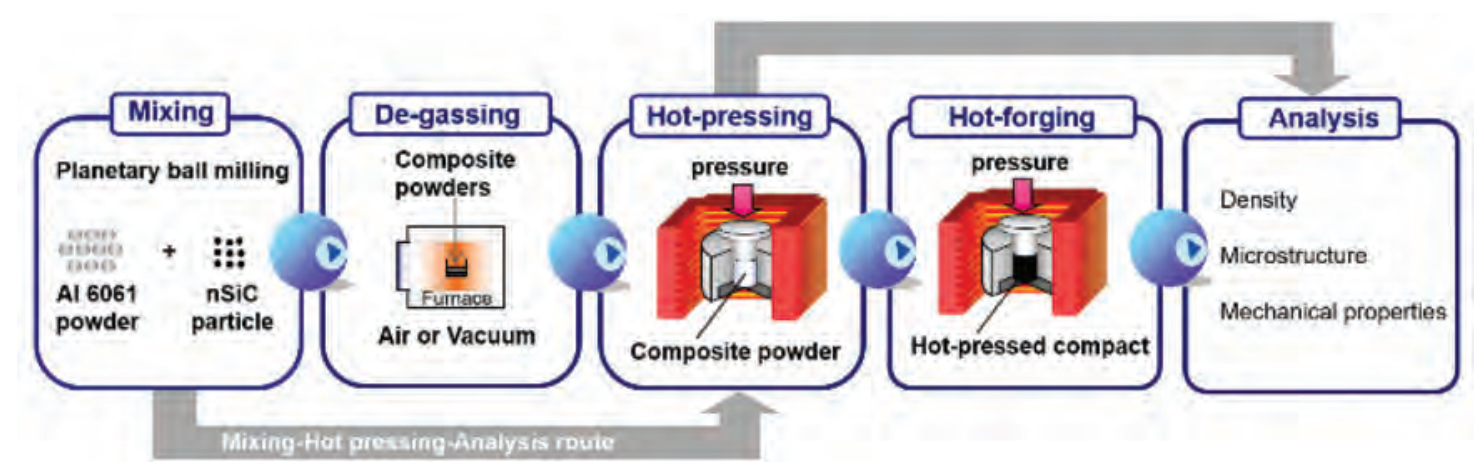

Figure 1. Fabrication procedure of $\mathrm{nSiC}-\mathrm{Al} 6061$ composites. 
at $0.42 \mathrm{~mm} / \mathrm{min}$ (strain rate: $10^{-3} \mathrm{~s}^{-1}$ ). A four-point bend (4PB) test was performed using the $150-\mathrm{kN}$ servohydraulic test machine (Walter + Bai and DionSTAT software). The sample dimensions were approximately $3 \times$ $5 \times 22 \mathrm{~mm}^{3}$. The test fixture upper span length $\left(L_{i}\right)$ was $6.5 \mathrm{~mm}$, while the lower length $(L)$ was $19.5 \mathrm{~mm}$ (span ratio of 1/3). All of mechanical properties of samples were measured along to transverse direction of applied high pressure.

The test was performed with position control at a constant speed of $1 \mathrm{~mm} / \mathrm{min}$. X-ray diffraction (XRD) patterns were measured using an X'Pert Pro diffractometer (PANAlytical) with $\mathrm{Cu}-\mathrm{K}_{\alpha}$ radiation $(\lambda=1.54056 \AA, 45 \mathrm{kV}$, and $40 \mathrm{~mA}$ ) in the $2 \theta$ range $20-80^{\circ}$ using a linear detector (X'Celerator). A step size of $0.0167^{\circ}$ and scan rate of $0.05^{\circ} / \mathrm{s}$ were used. The crystallite sizes were calculated by the Scherrer equation [22].

\section{RESULTS AND DISCUSSION}

The initial Al 6061 powder had particles with round shapes and broad size distribution. The $\mathrm{nSiC}$ particles had crystalline structures and were highly agglomerated (Figs. 2(a and b)), as the physical energy generated during the high-energy ball milling was efficiently transferred to the Al particles with relatively large sizes, and the soft $\mathrm{Al}$ particles were plastically deformed. It was very challenging to observe the $\mathrm{nSiC}$ particles in the composite powder after the high-energy ball milling. In general, agglomerated nanoparticles can be observed through SEM-level analyses. However, we could not observe the nSiC particles in the composite powder, which implies that they were well dispersed. However, the dispersivity of the small amount of $\mathrm{nSiC}$ particles in the $\mathrm{Al}$ powders should be carefully investigated. The milled $1 \mathrm{vol} \% \mathrm{nSiC}-\mathrm{Al} 6061$ composite powder has distinct flake shapes with an average size of $50 \mu \mathrm{m}$ (Fig. 2(c)).

The HPed composite was highly densified, up to a relative density of $99.9 \%$, higher than that of the $\mathrm{Al} 6061$ alloy bulk $(99.5 \%)$, which implies that the addition of $\mathrm{nSiC}$ did not act as a densification barrier during the HP.

Therefore, HP is a very efficient approach to densify the nSiC-Al 6061 composite powders.

The microstructure analysis shows that the grains of the HPed 1 vol.\% nSiC-Al 6061 in the air atmosphere had


Figure 3. Microstructures of the $\mathrm{Al} 6061$ alloy bulk and 1 vol.\% nSiCAl 6061 composite: (a and b) Transverse and (c and d) longitudinal cross sections.

Table I. Density and Vickers hardness results of the Al 6061 alloy bulk and 1 vol.\% nSiC-Al 6061 composite.

\begin{tabular}{lcccc}
\hline & $\begin{array}{c}\text { Theoretical } \\
\text { density } \\
\left(\mathrm{g} / \mathrm{cm}^{3}\right)\end{array}$ & $\begin{array}{c}\text { Relative } \\
\text { density } \\
(\%) \pm 0.5 \%\end{array}$ & $\begin{array}{c}\text { Hardness } \\
(\mathrm{HV} 10) \pm 3\end{array}$ & $\begin{array}{c}\text { Indentation } \\
\text { modulus } \\
\left(\mathrm{kN} / \mathrm{mm}^{2}\right) \pm 5\end{array}$ \\
\hline Al 6061 Bulk & 2.713 & 99.5 & 33 & 71 \\
$\mathrm{Al} 6061-1$ vol.\%nSiC & 2.719 & 99.9 & 86 & 72 \\
$\quad$ composite & & & & \\
\hline
\end{tabular}

sizes of approximately $20-40 \mu \mathrm{m}$, oriented in a plane perpendicular to the consolidation direction, which is most likely attributed to the flake-like morphology of the HEM 1 vol.\% nSiC-Al 6061 powder (Figs. 2(c) and 3). The Vickers hardness of the 1 vol.\% nSiC-Al 6061 composite was three times higher than that of the pure Al 6061 alloy bulk fabricated with the same processing parameters, as shown in Table I. The indentation moduli of the composite and pure Al 6061 had similar values.

The $0.2 \%$-offset yield strength in the compression test of the 1-vol.\% composite was approximately $151 \mathrm{MPa}$, higher than that of the bulk of approximately $58 \mathrm{MPa}$, as shown in Figure 4 and Table II. The compressive strength of the composite was $245 \mathrm{MPa}$; the fracture strength of the bulk could not be measured owing to its high ductility and equipment strain limit (29\%). After
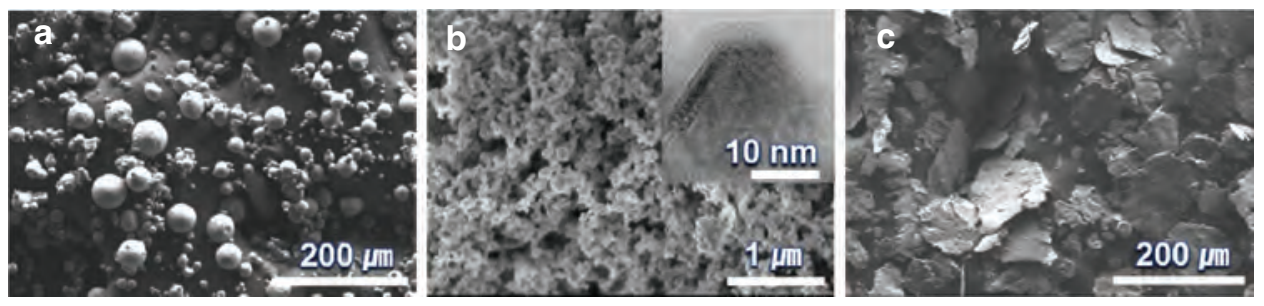

Figure 2. SEM images of the (a) gas-atomised Al 6061 powder, (b) nSiC particles (the inset shows a transmission electron microscopy (TEM) image), and (c) milled 1-vol.\%-nSiC Al 6061 composite powder. 


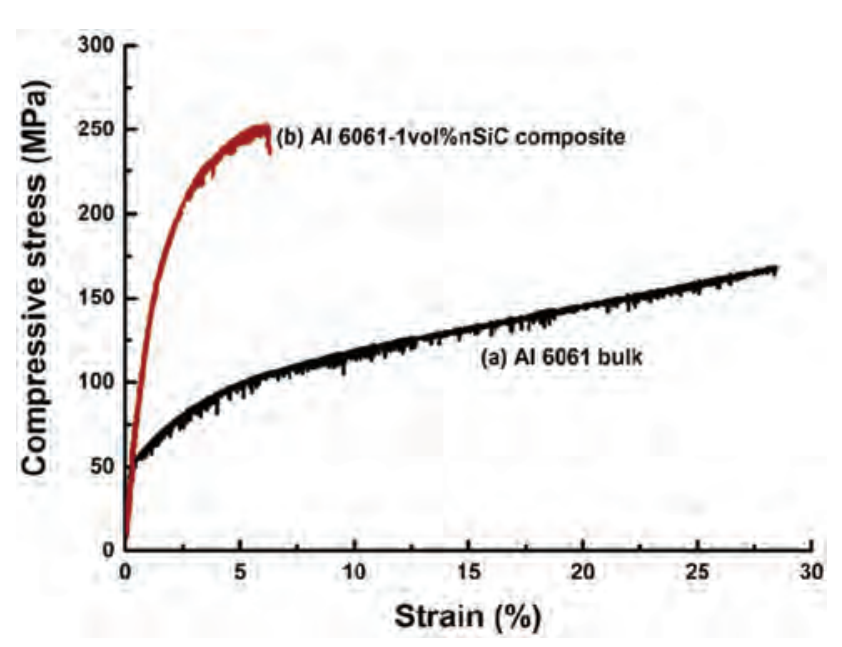

Figure 4. Compressive stress-strain curves of the (a) Al 6061 alloy bulk and (b) 1 vol.\% nSiC-Al 6061 composite.

the initial fracture in the composite, the composite exhibited a gradual-stress-decrease behaviour, as shown in Figure 4(b). This implies that the applied load was well transferred to the $\mathrm{Al} 6061$ and $\mathrm{nSiC}$ composite region with a high yield strength, leading to the gradual fracture stressstrain behaviour [23, 24]. The strain-stress behaviours of the composite and bulk are very different, as shown in Table II. The plastic deformation is decreased when the strength increases, which is a general behaviour of composite materials. Despite the small amount (1 vol\%), $\mathrm{nSiC}$ significantly enhanced the yield strength and compression strength of the HPed $\mathrm{nSiC}$ reinforced Al 6061-matrix composite.

The flexural strength of the composite had a higher value of $488 \mathrm{MPa}$ with a deflection value of $0.86 \mathrm{~mm}$; a higher yield strength (almost two times) was achieved, compared to that of the bulk. The flexural strength of the Al 6061 alloy bulk could not be measured owing to its high ductility and equipment limit $(1.5 \mathrm{~mm})$. However, the flexural strength of $\mathrm{Al} 6061$ saturated before the measurement equipment limitation was reached. Therefore, the results can be compared with those of the composite material.

The 1-vol.\% composite exhibited a four times higher yield strength in the tensile test, while the tensile strength was increased to $337 \mathrm{MPa}$, compared to $124 \mathrm{MPa}$ of the Al 6061 alloy bulk, as shown in Table II. Nevertheless, the elongation of the composite was five times lower than that of the bulk. The above results show that the yield and fracture strengths of the 1-vol\% composite were higher than those of the bulk regardless of the test conditions, which implies that $\mathrm{nSiC}$ efficiently reinforced the Al 6061 alloy matrix. The possibility for a further elongation increase was investigated using 1 vol.\% nSiC-Al 6061 composites produced under different conditions.

Figures 5(a)-(d) show microstructures of the HPed composite materials with heat-treated composite powders in the furnace under air atmosphere and vacuum, respectively. They show similar morphologies; however, the grain size of the sample heated under vacuum was larger than that of the sample heated under the air atmosphere. This suggests that the strength of the sample heated under vacuum is lower than that of the sample heated in the air atmosphere owing to the grain growth. Figures 5(e)-(h) show microstructures of the HPed and HFed composites using heat-treated composite powders in the air atmosphere and vacuum, respectively. We could observe finer microstructures in both cases compared to those of the samples obtained without HF. The transverse cross section of the HFed composite with the heated composite powder in vacuum showed the largest grain size (Fig. 5(g)).

It is expected that the composite with larger grains may exhibit a low strength and better ductility owing to release of residual stress. However, the results show that for different heat-treatment atmospheres, the grain sizes differ even though the temperature and time of the heat treatment are the same, which is reflected in the microstructures of the HPed composite materials.

The crystallite sizes of $\mathrm{Al}$ in the composites were larger than those in the $\mathrm{Al} 6061$ bulk regardless of the processing methods owing to the pinning effect [25] upon the addition of the nSiC particles, as shown in Table III. The samples processed in the air atmosphere had larger crystallite sizes compared to the vacuum-treated composites, which implies that the crystallites were highly restrained in the vacuum treatment. The HF increased the crystallite size of $\mathrm{Al}$ in both atmospheres owing to the applied secondary high pressure. This implies that the crystallite size can be controlled through the processing method and atmosphere, directly affecting the strength and ductility of the materials. These results explain the highest elongation in the composite obtained with vacuum degassing, HP, and HF.

The tensile strengths and elongations of the composite materials fabricated under the different processing

Table II. Values of mechanical properties obtained by different methods for the Al 6061 alloy bulk and 1-vol.\% composite.

\begin{tabular}{|c|c|c|c|c|c|c|c|c|c|}
\hline \multirow[b]{2}{*}{ Sample } & \multicolumn{3}{|c|}{ Compression test } & \multicolumn{3}{|c|}{ Tensile test } & \multicolumn{3}{|c|}{ Four-point bending test } \\
\hline & $\begin{array}{c}0.2 \% \text { offset } \\
\text { yield strength } \\
(\mathrm{MPa}) \pm 5 \%\end{array}$ & $\begin{array}{c}\text { Compressive } \\
\text { strength } \\
(\mathrm{MPa}) \pm 5 \%\end{array}$ & $\begin{array}{l}\text { Strain } \\
(\%) \pm 2\end{array}$ & $\begin{array}{l}0.2 \% \text { offset } \\
\text { yield strength } \\
(\mathrm{MPa}) \pm 5 \%\end{array}$ & $\begin{array}{c}\text { Tensile } \\
\text { strength } \\
(\mathrm{MPa}) \pm 5 \%\end{array}$ & $\begin{array}{l}\text { Elongation } \\
\quad(\%) \pm 1\end{array}$ & $\begin{array}{l}0.2 \% \text { offset } \\
\text { yield strength } \\
(\mathrm{MPa}) \pm 5 \%\end{array}$ & $\begin{array}{c}\text { Flexural } \\
\text { strength } \\
(\mathrm{MPa}) \pm 5 \%\end{array}$ & $\begin{array}{l}\text { Deflection } \\
(\mathrm{mm}) \pm 0.2\end{array}$ \\
\hline Al 6061 bulk & 58.3 & 170.0 & 29 & 55.2 & 124.0 & 25.0 & 75.0 & 255.3 & 1.5 \\
\hline $\begin{array}{l}\text { Al } 6061-1 \text { vol. } \% \text { nSiC } \\
\text { composite }\end{array}$ & 151.3 & 245.2 & 8.1 & 201.9 & 336.5 & 5.2 & 130.0 & 488.0 & 0.86 \\
\hline
\end{tabular}



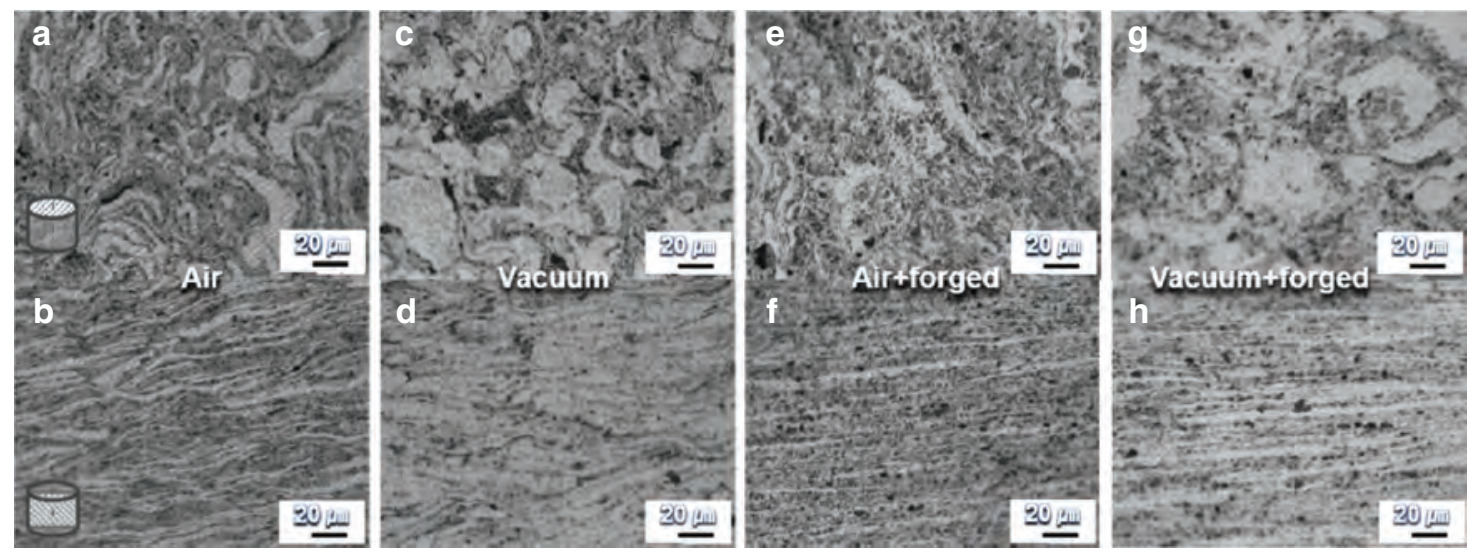

Figure 5. Microstructures of the 1 vol.\% nSiC-Al 6061 composites obtained under different processing conditions. Cross-sections of the samples ( $\mathrm{a}$ and b) HPed in the air atmosphere, (c and d) HPed in vacuum, (e and f) HPed and HFed in the air atmosphere, and ( $\mathrm{g}$ and $\mathrm{h}$ ) HPed and HFed in vacuum.

Table III. Crystallite sizes of $\mathrm{Al}[111]$ in the 1 vol.\% nSiC-Al 6061 composites obtained with different processing methods.

\begin{tabular}{|c|c|c|c|}
\hline Sample & Degassing & Method & $\begin{array}{c}\text { Crystallite size } \\
\text { of } \mathrm{Al} \pm 10 \%\end{array}$ \\
\hline Pure Al 6061 Bulk & Air & Hot-pressing & 320 \\
\hline $\begin{array}{l}\text { Al } 6061-1 \text { vol. } \% \text { nSiC } \\
\text { composite }\end{array}$ & Air & Hot-pressing & 281 \\
\hline $\begin{array}{l}\text { Al } 6061-1 \text { vol. } \% \mathrm{nSiC} \\
\text { composite }\end{array}$ & Air & $\begin{array}{l}\text { Hot-pressing and } \\
\text { forging }\end{array}$ & 304 \\
\hline $\begin{array}{l}\text { Al } 6061-1 \text { vol. } \% \text { nSiC } \\
\text { composite }\end{array}$ & Vacuum & Hot-pressing & 234 \\
\hline $\begin{array}{l}\text { Al } 6061-1 \text { vol. } \% \text { nSiC } \\
\text { composite }\end{array}$ & Vacuum & $\begin{array}{l}\text { Hot-pressing and } \\
\text { forging }\end{array}$ & 248 \\
\hline
\end{tabular}

conditions were measured. The results of the tensile test showed a significant improvement in ductility, as shown in Figure 6. The vacuum degassing led to an increase in elongation of approximately 30\%. The HPed and HFed composite materials of the degassed composite powders in the air atmosphere had a maximum increase in elongation of approximately $80 \%$. This suggested that the ductility of the 1 vol.\% nSiC-Al 6061 composites can be further improved by degassing in vacuum and HF.

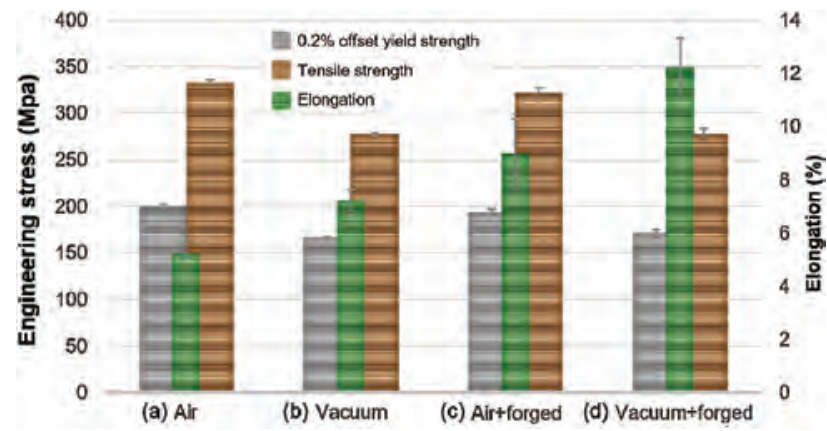

Figure 6. Tensile properties of the 1 vol.\% nSiC-Al 6061 composites, HPed in the (a) air atmosphere and (b) vacuum, and HPed and HFed in the (c) air atmosphere and (d) vacuum.
The elongation was increased by $140 \%$ owing to the efficient release of residual stress and better interface adhesion between $\mathrm{nSiC}$ and $\mathrm{Al}$ matrix induced by the applied high pressure during the HP process. However, the tensile strength was slightly decreased by $17 \%$ (Fig. 6). Therefore, controlled strength and elongation of the 1-vol.\% composites could be achieved by applying controlled fabrication procedures.

In the field of materials engineering, it is important to provide not only high-strength but also high-ductility materials. Therefore, we believe that the composites obtained using the proposed processes can be used as engineering materials with precisely controlled mechanical properties. The ductility increase is also reflected in the fracture surfaces of the tensile specimens.

Compared to the HPed composites of the degassed powders in the air atmosphere and vacuum, a smaller increase in ductility and less dimples were observed in the sample treated under the air atmosphere (Figs. 7(a and c)). Many dimples were observed in the degassed samples with

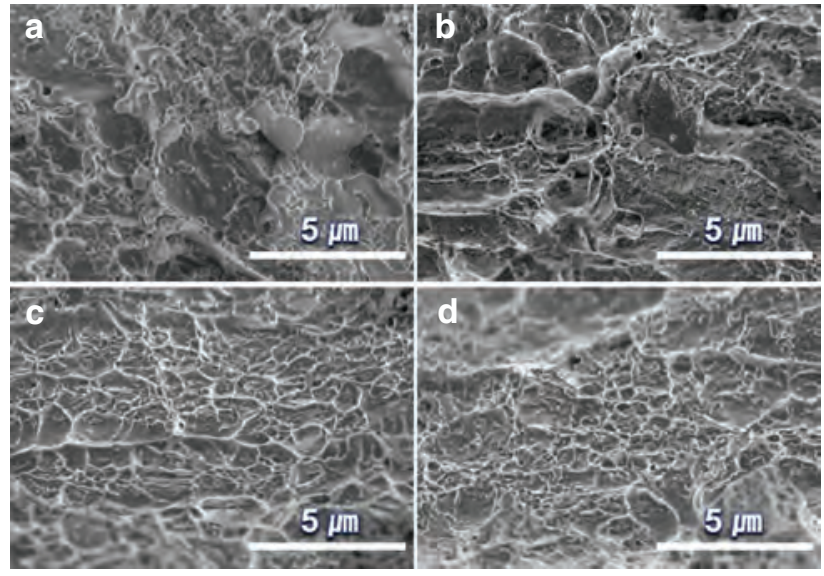

Figure 7. Fracture surfaces of the 1 vol. $\%$ nSiC-Al 6061 composites, HPed in the (a) air atmosphere and (b) vacuum, and HPed and HFed in the (c) air atmosphere and (d) vacuum. 

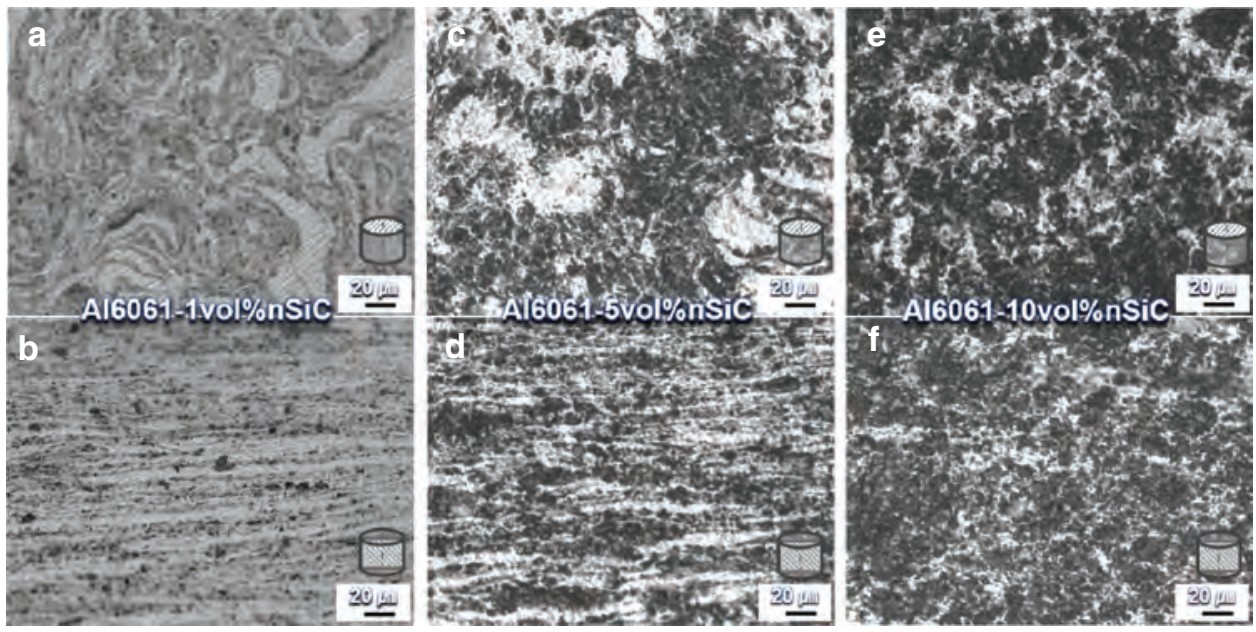

Figure 8. Microstructures of the $\mathrm{nSiC}$ reinforced $\mathrm{Al} 6061$ composites fabricated by $\mathrm{HP}$ followed by $\mathrm{HF}$ with $\mathrm{nSiC}$ contents of (a and b) 1 , (c and d) 5, and (e and f) 10 vol.\%.

Table IV. Properties of the composites with different $\mathrm{nSiC}$ volume fractions fabricated by HP followed by HF processes of degassed powders in vacuum.

\begin{tabular}{lccccc}
\hline Sample & $\begin{array}{c}\text { Theoretical density } \\
\left(\mathrm{g} / \mathrm{cm}^{3}\right)\end{array}$ & $\begin{array}{c}\text { Relative density } \\
(\%) \pm 0.5 \%\end{array}$ & $\begin{array}{c}0.2 \% \text { offset yield } \\
\text { strength }(\mathrm{MPa}) \pm 5 \%\end{array}$ & $\begin{array}{c}\text { Tensile strength } \\
(\mathrm{MPa}) \pm 5 \%\end{array}$ & $\begin{array}{c}\text { Elongation } \\
(\%) \pm 1\end{array}$ \\
\hline Al 6061-1 vol.\%nSiC composite & 2.719 & 99.9 & 173.5 & 288 & 12 \\
Al 6061-5 vol.\%nSiC composite & 2.742 & 100.6 & 183.2 & 312 & 8 \\
Al 6061-10 vol.\%nSiC composite & 2.771 & 100.9 & 202.6 & 351 & 3 \\
\hline
\end{tabular}

HF (Figs. 7(b and d)). The finest dimples were observed in the vacuum-treated sample with HF; this morphology could induce the highest elongation, as shown in Figures 6 and $7(\mathrm{~d})$. In other words, the microstructure control of the 1 -vol\% composites directly affect the composite properties including the tensile strength and elongation. Owing to the significant increase in ductility, the degassing in vacuum and HF were chosen as a processing technology to investigate the effect of the increased $\mathrm{nSiC}$ particle content on the mechanical properties.

Figure 8 shows microstructures of the $\mathrm{nSiC}$ reinforcedAl 6061 alloy matrix composite materials with $\mathrm{nSiC}$ contents of 1,5 , and 10 vol.\%. In the $10-$ vol.\% composite, it was very difficult to distinguish grain boundaries, compared to those in the 1- and 5-vol.\% composites. However, we could achieve bulk composite materials with high amounts of $\mathrm{nSiC}$ particles added in the Al 6061 alloy matrix.

Tensile tests were performed to study the effect of the increased $\mathrm{nSiC}$ content on the elongation and strength. The composites were almost fully densified; for the 5- and 10vol.\% composites, values different than the theoretical full densities were observed, as shown in Table IV, which was most likely observed owing to test equipment errors. The $0.2 \%$-offset yield strength and tensile strength increased with the volume fraction of $\mathrm{nSiC}$. On the other hand, the elongation significantly decreased with the increase in the nSiC content, as shown in Table IV.
This shows that the nSiC particles can be used as a strengthening medium in the Al 6061 alloy matrix composites. However, it is worth noting that they induced brittleness of the materials. We can control the tensile strength and elongation of the composites by controlling the content of $\mathrm{nSiC}$ particles. This simple approach enables cost reduction and application to precision engineering structures. The strengthening mechanism by the addition of $\mathrm{nSiC}$ particles and processing parameters of the $\mathrm{nSiC}$ reinforced Al 6061 alloy matrix composite materials should be investigated in detail considering Orowan looping, thermal mismatch, shear-lag model, work-hardening, etc. [26], which will be subject of our following studies.

\section{CONCLUSIONS}

nSiC reinforced Al 6061-alloy matrix composites were fabricated using high-energy mechanical ball milling, HP, and HF. Different tests were performed including compression, four-point bending, and tensile tests, to evaluate the mechanical properties of the composites. The influences of the processing parameters on the mechanical properties, particularly the tensile behaviours of the composites, were investigated. We summarised the following conclusions of this study:

(1) The Vickers hardness and tensile strength of the 1 vol.\% nSiC-Al 6061 composite materials were approximately three times higher than those of the pure Al 6061 alloy bulk. 
(2) The degassing in vacuum led to an increase in elongation of approximately $30 \%$ and decrease in $0.2 \%$-offset yield strength of $20 \%$.

(3) The HF led to an increase in elongation of up to $80 \%$ and decrease in $0.2 \%$-offset yield strength of approximately $5 \%$.

(4) The vacuum degassing with HF led to an increase in elongation of approximately $140 \%$ and decrease in $0.2 \%$ offset yield strength of approximately $17 \%$.

(5) The crystallite sizes of $\mathrm{Al}$ in the composites were larger than that of the $\mathrm{Al} 6061$ bulk regardless of the processing methods due to the pinning effect upon the addition of $\mathrm{nSiC}$ particles.

(6) The increased $\mathrm{nSiC}$ particle content in the $\mathrm{Al} 6061$ alloy matrix from 1 to 5 and 10 vol.\% led to a decrease in elongation of up to $75 \%$ and increase in $0.2 \%$-offset yield strength of $27 \%$.

These results showed that the small amounts of $\mathrm{nSiC}$ particles functioned as efficient reinforcement materials in the $\mathrm{Al}$ alloy matrix composites and that the strength and ductility of the $\mathrm{nSiC}$ reinforced $\mathrm{Al}$ alloy composite materials can be controlled by adjusting the processing parameters and $\mathrm{nSiC}$ content.

\section{References and Notes}

1. Tjong, S.C., 2008. Novel nanoparticle-reinforced metal matrix composites with enhanced mechanical properties. Advanced Engineering Materials, 9(8), pp.639-652.

2. Bakshi, S.R., Lahiri, D. and Agarwal, A., 2010. Carbon nanotube reinforced metal matrix composites-A review. International Materials Reviews, 55(1), pp.41-64.

3. Kollo, L., Leparoux, M., Bradbury, C.R., Jaggi, C. and CarrenoMorelli, E., 2010. Investigation of planetary milling for nano-silicon carbide reinforced aluminium metal matrix composites. Journal of Alloys Compounds, 489(2), p.394.

4. Kollo, L., Leparoux, M., Bradbury, C.R., Kommel, L., CarreñoMorelli, E. and Rodríguez-Arbaizar, M., 2010. Hardness of Hot Consolidated Al-SiC Nanocomposites from Planetary Milled Powders. Proceedings of the World Powder Metallurgy Congress and Exhibition, October 10-14; Italy, Florence. pp.1-4.

5. Rodríguez-Arbaizar, M., Hamdan, H., Leparoux, M., Kollo, L. and Kwon, H. and Carreño Morelli, E., 2010. Net-Shape A16061/SiC Nanocomposites by Powder Injection Moulding. Proceedings of Powder Metallurgy World Congress PM2010, October 10-14; Italy, Florence. pp.429-434.

6. Kwon, H., Bradbury, C.R. and Leparoux, M., 2011. Fabrication of functionally graded carbon nanotube-reinforced aluminum matrix composite. Advanced Engineering Materials, 13(4), pp.325-329.

7. Jiang, L., Li, Z., Fan, G., Cao, L. and Zhang, D., 2012. Strong and ductile carbon nanotube/aluminum bulk nanolaminated composites with two-dimensional alignment of carbon nanotubes. Scripta Materialia, 66(6), pp.331-334.

8. Li, Y., Zhao, Y.H., Ortalan, V., Liu, W., Whang, Z.H., Vogt, R.G., Browning, N.D., Laverinia, E.J. and Schoeung, J.M., 2009. Investigation of aluminum-based nanocomposites with ultra-high strength. Materials Science and Engineering: A, 527(1-2), pp.305-316.
9. Kwon, H., Cho, S., Leparoux, M. and Kawasaki, A., 2012. Dualnanoparticulate-reinforced aluminum matrix composite materials. Nanotechnology, 23(22), p.225704.

10. Lauri, K., Marc, L., Christopher R. Bradbury, Christian, J., Efrain, C.M. and Mikel, R.A., 2010. Investigation of planetary milling for nano-silicon carbide reinforced aluminium metal matrix composites. Journal of Alloys and Compounds, 489(2), pp.394-400.

11. Mishra, A.K., Sheokand, R. and Srivastava, R.K., 2012. Tribological behavior of Al-6061/SiC metal matric composite by Taguchi's techniques. International Journal of Scientific and Research Publications, 2(10), pp.1-8.

12. Soltani, S., Khosroshahi, R.A., Mousavian, R.T., Jiang, Z.Y., Boostani, A.F. and Brabazon, D., 2017. Stir casting process for manufacture of Al-SiC composites. Rare Metals, 36(7), pp.581-590.

13. Sijo, M.T. and Jayadevan, K.R., 2016. Analysis of stir cast aluminium silicon carbide metal matrix composite: A comprehensive review. Procedia Technology, 24, pp.379-385.

14. Kant, S. and Verma, A.S., 2017. Stir casting process in particulate aluminium metal matrix composite: A review. International Journal of Mechanics and Solids, 12(1), pp.61-69.

15. El-Day, A.A., Abdelhameed, M., Hashish, M. and Eid, A.M., 2012. Synthesis of $\mathrm{Al} / \mathrm{SiC}$ nanocomposite and evaluation of its mechanical properties using pulse echo overlap method. Journal of Alloys and Compounds, 542, pp.51-58.

16. El-Day, A.A., Abdelhameed, M., Hashish, M. and Daoush, W.M. 2013. Fabrication of silicon carbide reinforced aluminum matrix nanocomposites and characterization of its mechanical properties using non-destructive technique. Materials Science and Engineering: A, 559, pp.384-393.

17. Guillou, M.O., Henshall, J.L. and Hooper, R.N., 1998. Indentation fracture and soft impresser fatigue in sapphire and polycrystalline alumina. International Journal of Refractory Metals and Hard Materials, 16(4-6), pp.323-329.

18. Leconte, Y., Leparoux, M., Portier, X. and Herlin-Boime, N., 2008. Plasma Chemistry and Plasma Processing, 28(2), pp.233-248.

19. European Committee for Standardization, 2003, Metallic Materials-Instrumented Indentation Test for Hardness and Materials Parameters-Part 1: Test Method, EN-ISO 14577:2003, European Committee for Standardization.

20. European Committee for Standardization, 2010, Metallic Materials-Tensile Testing-Part 1: Method of Test at Room Temperature, EN-ISO 6892-1:2010, European Committee for Standardization.

21. Rabei, A., Kim, B.N., Enoki, M. and Kishi, T., 1996. Al fracture behaviour in $6061 \mathrm{Al}$ alloy matrix composites with different reinforcements. Materials Transactions, JIM, 37(5), pp.1148-1155.

22. Monshi, A., Foroughi, M.R. and Monshi, M.R., 2012. Modified scherrer equation to estimate more accurately nano-crystallite size using XRD. World Journal of Nano Science and Engineering, 2 , pp. $154-160$

23. Kim, K.T., Cha, S.I. and Hong, S.H., 2006. Mechanical and electrical properties of cross-linked carbon nanotubes. Materials Science and Engineering: A, 430, pp.27-33.

24. Kwon, H., Park, D., Silvain, J.F. and Kawasaki, A., 2010. Investigation of carbon nanotube reinforced aluminum matrix composite materials. Composites Science and Technology, 70(3), pp.546-550.

25. Yu, R.H., Basu, S., Zhang, Y., Parvizi-Majidi, A. and John Q.X., 1999. Pinning effect of the grain boundaries on magnetic domain wall in FeCo-based magnetic alloys. Journal of Applied Physics, 85, pp.6655-6659.

26. George, R., Kashyap, K.T., Rahul, R. and Yamadagni, S., 2005. Strengthening in carbon nanotube/aluminium (CNT/Al) composites. Scripta Materilia, 53(10), pp.1159-1163.

Received: 6 March 2019. Accepted: 27 August 2019. 